\title{
KVĖPAVIMO SUTRIKIMŲ MIEGANT DIAGNOSTIKA
}

\author{
DOC. DR. SKAIDRIUS MILIAUSKAS
}

KMU PULMONOLOGIJOS IR IMUNOLOGIJOS KLINIKA

Reikšminiai žodžiai: obstrukcinė miego apnėja, centrinė miego apnėja, mieguistumas, polisomnografijos tyrimas. Santrauka. Straipsnyje pateikiami naujausi duomenys apie kvėpavimo sutrikimų miegant diagnostiką, mieguistumo dieną tyrimus, aptariami polisomnografijos principai.

Miego apnejja - kvėpavimo pauzė miegant, trunkanti trumpiausiai 10 sekundžių. Apie 90 proc. visų atveju miego apnejja yra obstrukcinè, atsirandanti dèl viršutinių kvẻpavimo takų pokyčių. Obstrukcinè miego apnèja (OMA) yra dažniausia iš kvėpavimo sutrikimų miegant. Centrinė miego apnejja pasitaiko gerokai rečiau (iki 10 proc. visų apnèjos atvejų) ir dažniausiai pasireiškia Cheyne-Stokes kvėpavimu ar periodiniu kvėpavimu aukštikalnèse.

Kalbèdami apie OMA, turime galvoje obstrukcinès miego apnèjos sindromą. Obstrukcinès miego apnèjos sindromas - objektyviai nustatyti kvèpavimo sutrikimai miegant (ne mažiau kaip penki per valanda), kurie salygoja klinikinius požymius (dažniausiai mieguistuma) diena ir lemia darbingumo bei sveikatos pokyčius.

Amerikos miego medicinos akademija (angl. American Academy of Sleep Medicine) ir Europos respiratologu draugija (angl. European Respiratory Society) 1999 metais priemé OMA diagnostikos rekomendacijas. Remiantis A, B ir C kriterijais, OMA diagnozė patvirtinama arba atmetama. OMA diagnozei patvirtinti turi būti vienas $A$ arba $B$ ir būtinai $C$ kriterijus.

A - padidejęs mieguistumas dieną, nepaaiškinamas kitomis priežastimis.

B - du arba daugiau iš šių požymių, nepaaiškinami kitomis priežastimis:

- žiopčiojimas miegant;

- prabudimú kartojimasis;

- po miego nesijaučiama pailsèjus;

- silpnumas dieną;

- sutrikęs gebejjimas sutelkti dèmesí.

C - Stebint nakti polisomnografijos metodu nustatoma mažiausiai penki obstrukcinès miego apnejjos epizodai per valandą - tai gali būti apnejjos, hipopnèjos arba kvėpavimo pastangu sąlygoti daugkartiniai trumpi prabudimai.

\section{OBSTRUKCINĖS MIEGO APNĖJOS KLINIKI- NIAI POŽYMIAI}

Pagrindiniai OMA klinikiniai požymiai yra knarkimas naktị ir mieguistumas dieną (1 lentelè). Klinikiniai požymiai 1 lentelèje pateikti mažejjančio dažnumo tvarka.

\begin{tabular}{ll}
\hline lentelè. OBSTRUKCINĖS MIEGO APNĖJOS KLINIKINIAI POŽYMIAI \\
\hline Dienos simptomai & Nakties simptomai \\
\hline Padidèjęs mieguistumas & Knarkimas \\
\hline Sutrikęs darbas ir mokymasis & $\begin{array}{l}\text { Kitu pastebėti kvėpavimo } \\
\text { sustojimai }\end{array}$ \\
\hline Rytiniai galvos skausmai & Neramus miegas \\
\hline Intelekto pokyčiai & Nemiga \\
\hline Sutrikusi atmintis & Žiopčiojimas ir dusulys \\
\hline $\begin{array}{l}\text { Sutrikęs gebèjimas sutelkti } \\
\text { dėmesi }\end{array}$ & Pasikartojantys prabudimai \\
\hline Depresijos simptomai & Nikturija \\
\hline Rėmuo & Enurezė \\
\hline & Susilpnèjęs lytinis potraukis \\
\hline & Prakaitavimas \\
\hline & Širdies ritmo sutrikimai
\end{tabular}

Be mieguistumo, dažni asmenybės pokyčiai: agresyvumas, dirglumas, nerimas arba depresija. Nukenčia darbingumas, bendravimas šeimoje ir visuomeneje. Maždaug trečdaliui ligonių susilpnejja lytinis potraukis, vystosi impotencija. Iki penkiasdešimt procentų ligonių skundžiasi rytiniais arba naktiniais galvos skausmais, padažnejjusiu šlapinimusi naktį. Galvos skausmai paprastai tęsiasi 1-2 valandas, ir dèl to gali būti piktnaudžiaujama nesteroidiniais vaistais nuo uždegimo.

Be knarkimo, kuris būna visiems OMA sergantiems žmonèms, 75 proc. atvejų apnèjos epizodus pastebi miegantys kartu asmenys. Juos kvèpavimo pauzès išgąsdina, kartais ligonis būna purtomas tikintis, kad sugrị̌s kvėpavimas. Apnejja baigiasi žiopčiojimu, springimu ir kitais garsais. Vieni ligoniai dèl prabudinejjimo tiesiog bijo miegoti ir skundžiasi nemiga, kiti - miegodami blaškosi, pabudinèja daugybę kartu, miegas jiems nesuteikia poilsio.

\section{Mieguistumas: reikšmė ir tyrimai}

Mieguistumas - dažniausias OMA dienos simptomas. Mieguistumas gali būti lengvo laipsnio (norisi miego pavalgius pietus, susirinkime ar žiūrint televizorių), vidutinis ar net sunkus (užmiegama kalbant ar val- 


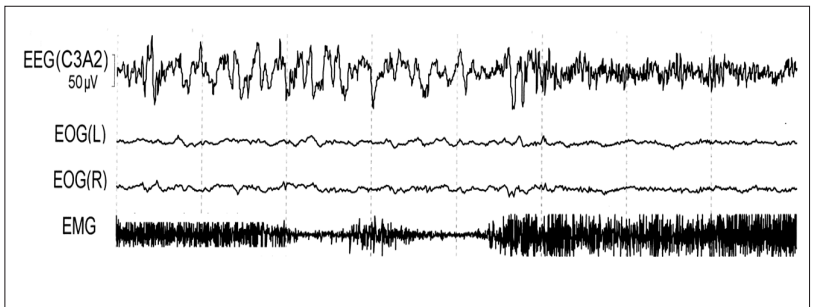

1 a pav. PRABUDIMAS EEG LĖTOJO MIEGO METU

gant) ir katastrofiškai pavojingas kitiems (užmiegama vairuojant). Apskritai nèra normalu būti mieguistam dieną pavalgius ar žiūrint televizorių. Net ir toks mieguistumas rodo, kad stokojama miego, ir OMA gali būti šito priežastis. Tiriant ligonius, būtina pasidomèti apie mieguistumą vairuojant, nes tai susiję su didesniu avarijų pavojumi ir kitų žmonių saugumu. OMA keletą kartu padidina eismo ịvykių riziką. Mieguistumas atsiranda dèl miego fragmentacijos, nes po kiekvieno apnejjos, hipopnejos ar RERA epizodo EEG nustatomas mikroprabudimas (angl. micro-arousal), sutrikdantis miego struktūrą. Mikroprabudimas - 3 sekundes ar ilgiau trunkantis EEG padažnejjimas po apnejjos arba hipopnejos (1 a pav.). Paradoksinio miego metu mikroprabudimas užrašomas tik tada, kai padažnėjus EEG kartu elektromiogramoje (EMG) fiksuojamas raumenų tonuso padidejimas ( $1 \mathrm{~b}$ pav.). Mieguistumui dieną turi itakos ir hipoksemijos gylis naktį.

Mieguistumas tiriamas objektyviais (instrumentiniais) ir subjektyviais (standartizuotais klausimynais) metodais. Objektyviam mieguistumo įvertinimui („auksinis" mieguistumo tyrimo standartas) yra atliekamas kartotinis užmigimo trukmès méginys (angl. Multiple sleep latency test, MSLT) bei budrumo palaikymo méginys (angl. Maintenance of Wakefullness Test, $M V T$ ). MSLT taikomas dažniausiai. Šio tyrimo principas - užmigimo laiko matavimas (iki 2 miego stadijos atsiradimo EEG) ipprastinès miego aplinkos sąlygomis (tamsa, tyla, gulejimas lovoje, nesipriešinimas miegui). Kartotinis užmigimo trukmès tyrimas atliekamas leidžiant tiriamajam penkis kartus užmigti kas dvi valandas. Kiekvienas bandymas nutraukiamas arba neužmigus per 20 minučių, arba užmigus 15 minučių, arba kai EEG užrašomi trys 30 sek. miego apnejjos epizodai. Išmatuojamas laikas iki užmigimo (miego latentiškumas) ir apskaičiuojamas visų penkių bandymų vidurkis. Miego latentiškumas, mažesnis nei 5 minutès, rodo, kad mieguistumas didelis, jeigu latentiškumas yra 5-10 minutès, - vidutinis, o jei daugiau kaip 10 minučiuc, - tai normalu.

Budrumo palaikymo mèginys atliekamas iš keturiu ar penkių méginių dviejų valandų intervalais, kai tiriamasis stengiasi neužmigti ramioje aplinkoje. Kiekvienas mėginys nutraukiamas užmigus (užrašius bet kurią miego stadiją EEG) arba jei per 20 minučių neužmiegama. Mieguistumas yra didelis, jei išmatuotas miego latentiškumas mažesnis nei 11 minučių.

Iš subjektyviųjų metodų dažniausiai naudojama Epworth mieguistumo skale (EMS) (2 pav.) EMS sukūrè Murray Johns Epworth Melburno ligoninejje. Šiame klausimyne yra aštuonios situacijos. Tiriamojo klausiama apie tikimybę užmigti (vertinama nuo 0 iki

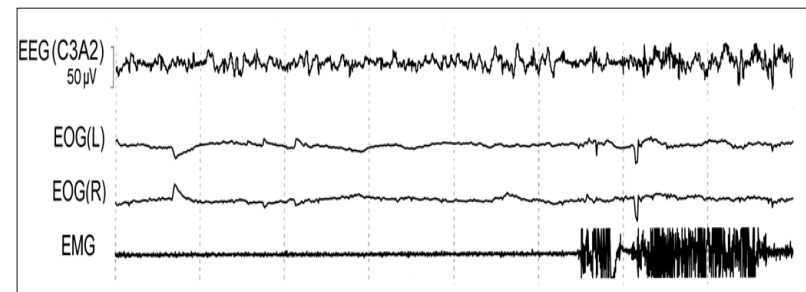

1 b pav. PRABUDIMAS EEG PARADOKSINIO MIEGO METU

3 balų). Didžiausia galima balų suma - 24. Kai suma viršija 10, konstatuojama, kad mieguistumas didelis. 1, 3, 6, 7 situacijose tiriamasis tikrai sèdi, 2, 4, ir 8 - greičiausiai sèdi, o 5 - guli.

Tirdamas ligonị, kuris skundžiasi padidejjusiu mieguistumu dieną, gydytojas turètų išsiaiškinti:

- ar pacientas knarkia su pertraukomis ar nepertraukiamai - geriausiai tai apibūdina miegantieji tame pačiame kambaryje;

- ar pacientas jaučiasi pailsèjęs po miego - dauguma OMA sergančių asmenų būna mieguisti ir pavargę visą dieną, o sergančius narkolepsija mieguistumas apima priepuoliais, kitu laiku jie būna žvalūs;

- ar pacientui būna hipnogoginių haliucinacijuc - jos būdingos narkolepsijai ir labai retos sergant OMA;

- ar mieguistumas labiau vargina darbo dienomis ar visada, ar naktị miegama pakankamai - ši informacija reikalinga, kad būtuc nustatytas lètinis miego stygius;

- ar alkoholis, vartojamas net ir nedideliais kiekiais, lemia neišsimiegojimą ar rytinius galvos skausmus - nustatyta, kad alkoholis sustiprina OMA klinikinius simptomus.

VARDAS, PAVARDE்
AMŽIUS (METAI) — LYTIS (VYRAS = V, MOTERIS -
TYRIMO DATA

Kokia tikimybė užsnūsti ar užmigti toliau išvardytomis aplinkybėmis, nepaisant tik nuovargio pojūčio? Tai turi atspindèti Jūsų gyvenseną šiomis dienomis. Jeigu pastaruoju laiku nebuvote tokiose situacijose, pabandykite issivaizduoti, kaip jose jaustumètès. Kiekvienai situacijai parinkite Jums tinkamiausio atsakymo numerị: 0 = niekada nesnaudžiu; 1 = nedidelè tikimybé užsnūsti; 2 = vidutinè tikimybè užsnūsti; 3 = didelè tikimybė užsnūsti.

\begin{tabular}{|c|c|}
\hline Situacija & Balai \\
\hline Sèdint ir skaitant & \\
\hline Žiūrint televizorių & \\
\hline $\begin{array}{l}\text { Ramiai sèdint viešoje vietoje } \\
\text { (pvz., teatre ar susirinkime) }\end{array}$ & \\
\hline $\begin{array}{l}\text { Valandą be pertraukos keliaujant } \\
\text { automobiliu keleivio vietoje }\end{array}$ & \\
\hline $\begin{array}{l}\text { Atsigulus pailsèti pietu metu, } \\
\text { kai leidžia aplinkybès }\end{array}$ & \\
\hline Sedint ir kalbantis su kuo nors & \\
\hline Ramiai sėdint, papietavus, negèrus alkoholiniu gèrimy & \\
\hline $\begin{array}{l}\text { Vairuojant automobili, stabtelèjus kelioms minutems } \\
\text { spūsties metu }\end{array}$ & \\
\hline
\end{tabular}

2 PAV. EPWORTH MIEGUISTUMO SKALĖ 


\section{Knarkimas - pagrindinis obstrukcinès miego apnèjos nakties simptomas}

Knarkimas - universalus OMA požymis. Ji lemia tos pačios viršutinius kvėpavimo takus siaurinančios priežastys kaip ir OMA. Knarkimo garsą sukelia viršutinių kvėpavimo takų minkštųjų audinių vibracija. Paprastai knarkti pradedama keletą metų prieš pastebint kvejpavimo pauzes. OMA sergantys ligoniai knarkia 80 decibelu ir stipresniu garsu. Negarsus knarkimas dažniausiai būna gerybinis - be apnèjos. Knarkia 60 proc. $41-65$ metu vyru ir 40 proc. šio amžiaus moterų. Knarkimas skiriasi intensyvumu ir kokybe. Jis priklauso nuo nakties laiko, miego stadijos, miegančiojo padėties, oro srovės greičio, anatominių nosiaryklès savybių. Nutukusio žmogaus knarkimo susilpnejjimas, kurị pastebi lovos partneris, gali būti sunkejjančios OMA požymis. Knarkimas, kuris pabudina pacientą, rodo, kad sergama OMA.

Alkoholis, vienas iš OMA ir knarkimą skatinančių veiksnių, gali knarkimą išprovokuoti sveikiems žmonėms; knarkiantiems laikinai paskatina atsirasti kvèpavimo pauzes, o sergantiems OMA lemia dar daugiau apnejos epizodų. Taigi alkoholis visais atvejais pasunkina kvèpavimą miegant.

Apžiūrint nosiaryklę, matyti padidejjusi liežuvio šaknis, išvešẻjęs minkštasis gomurys, liežuvẻlis. Nosiaryklès anatomija vertinama pagal Mallampati laipsnius. Šie nosiaryklès pokyčiai susiję su OMA ir knarkimo rizika (ypač III ir IV laipsnio pagal Mallampati).

Mallampati laipsnių požymiai:

$I^{\circ}$ - aiškiai matomos tonzilès, gomurio lankai, minkštasis gomurys.

$\mathrm{II}^{\circ}$ - matomas liežuvèlis, viršutinis tonzilių polius, gomurio lankai.

III $^{\circ}$ - matoma tik dalis minkštojo gomurio (gomurio lankai nematomi).

$I^{\circ}$ - matomas tiktai kietasis gomurys

\section{Kiti miego apnèjai būdingi klinikiniai požymiai}

60-70 proc. OMA sergančiu žmoniu turi antsvorio - kūno masès indeksas didesnis nei $28 \mathrm{~kg} / \mathrm{m} 2$ ar svoris viršija idealųji 20 proc. Nutukimas yra vienas svarbiausių apnejos rizikos veiksnių. Sergant OMA, dažna ir arterinè hipertenzija. Miego apnejja nustatoma mažiausiai 25 proc. žmonių, sergančių arterine hipertenzija, o arterinè hipertenzija - 40 proc. OMA sergančių žmonių. Rytiniai galvos skausmai - nespecifinis daugelio miego sutrikimų simptomas. Jis pasireiškia apie 20 proc. OMA ligoniu ir 25 proc. patiriančiųjų kitus miego sutrikimus. Rytiniai galvos skausmai būdingesni, kai kartu su OMA sergama arterine hipertenzija, depresija, migrena, veido ančiu ligomis, lètine obstrukcine plaučiuc liga (LOPL).

\section{OBSTRUKCINĖS MIEGO APNĖJOS DIAGNOSTIKA}

Itarus OMA, surenkama ligos anamnezè, atliekamas bendrasis klinikinis tyrimas, ịvertinami viršutiniai kvėpavimo takai, nustatomas mieguistumo lygmuo.

OMA patvirtinti būtinas vienas iš trijų miego tyrimų:

- visos nakties oksimetrija;

- ribotos apimties arba respiracinè polisomnografija, kai, be oksimetrijos, užrašomi dar keli papildomi parametrai: knarkimas, širdies susitraukimų dažnumas, oro srovė per nosí, krūtinès ląstos ir pilvo judesiai, koju judesiai;

- išsamus polisomnografijos tyrimas („auksinis“ OMA diagnozės standartas).

Nèra įrodymu, kad visais OMA atvejais diagnozei nustatyti būtinas išsamus polisomnografijos tyrimas. Tipiniais atvejais pakanka nakties oksimetrijos arba respiracinès polisomnografijos tyrimo. Tačiau, remiantis vien tik oksimetrija, galima suklysti. Rezultatai gali būti klaidingai neigiami esant Cheyne-Stokes kvèpavimui (širdies nepakankamumas persirgus insultu), mažas pradinis (dienos) įsotinimas deguonimi (sergant sunkia LOPL, esant lètiniam kvėpavimo nepakankamumui), jauniems pacientams ar nesant antsvorio.

Daugelyje šalių rutiniškai atliekama respiracinė polisomnografija.

Atliekant išsamų polisomnografijos tyrimą registruojama:

1. EEG (nustatomas būdravimas, miego stadijos, mikroprabudimai);

2. Elektrookuliograma (EOG) (paradoksiniam miegui nustatyti);

3. Elektromiograma (EMG) (raumenų tonusui ịvertinti);

4. EKG (širdies ritmo sutrikimams);

5. Oro srovè per nosi (apnèjai ir hipopnejjai);

6. Krūtinès ir pilvo judesiai (obstrukcinès ir centrinès miego apnèjos diferencinei diagnostikai);

7. Pulsoksimetrija (deguonies ịsotinimo sumažejjimui nustatyti);

8. Knarkimas (pašaliniai garsai);

9. Kojų judesiai (galūnių periodinių judesių sindromo diagnostikai);

10. Kūno padètis (su kūno padètimi susijusiems kvèpavimo sutrikimams diagnozuoti).

3 ir 4 paveiksluose pavaizduota sveiko žmogaus polisomnograma (ALICE 4 sistema). Tiriamasis nepertraukiamai kvėpuoja, adekvačiai juda krūtinè ir

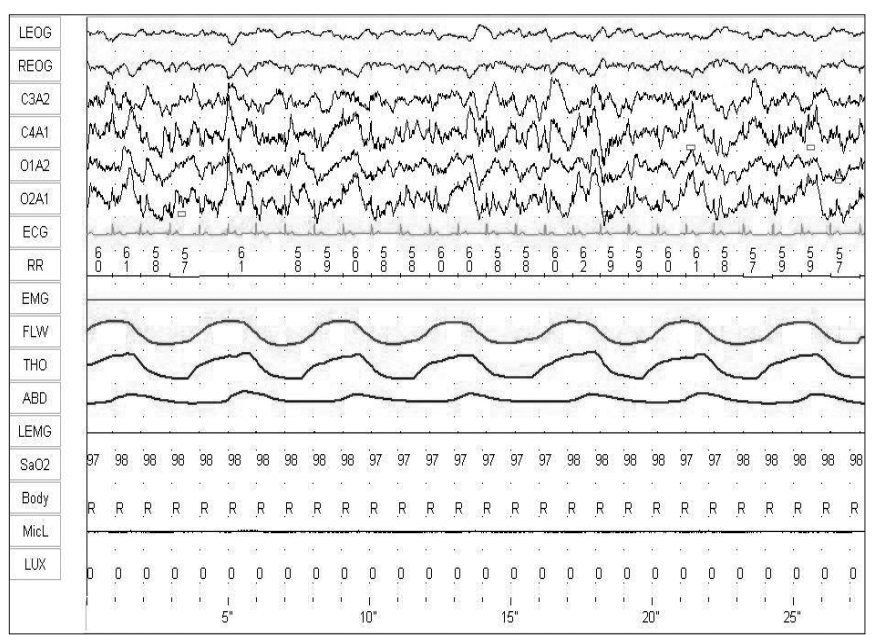

3 pav. NORMALI POLISOMNOGRAMA (30 SEK. 


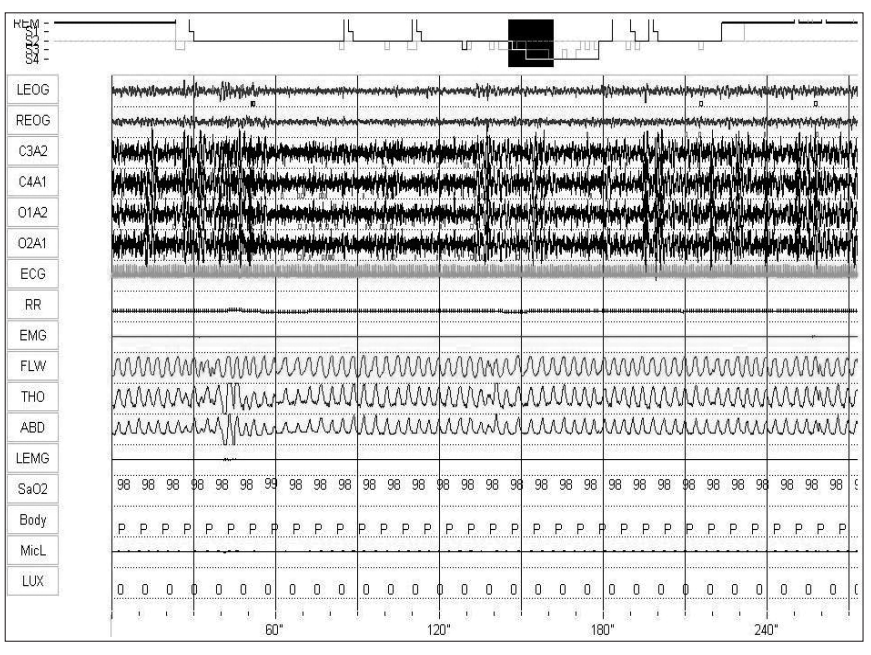

4 pav. NORMALI POLISOMNOGRAMA (5 MIN.)

pilvas, ìsotinimas deguonimi ryškiau nesumažèja.

Sergant OMA, kartojasi asfikcija ir po jos einantys hiperventiliacijos epizodai. 5 paveiksle matyti OMA ligonio polisomnograma (5 min.). Po asfikcijos sumažeja ịsotinimas deguonimi ir EEG užrašomas mikroprabudimas. Po mikroprabudimo paprastai pakanka kelių įkvejpimų, kad arterinio kraujo dujų sudètis taptų normali. İsotinimo deguonimi sumažèjimas priklauso nuo apnejos trukmès ir nuo deguonies kieko plaučiuose, kuris priklauso nuo plaučių tūrio bei gretutinių plaučių ligų. Nesant kito rizikos veiksnio, apnèja, trunkanti nuo 10 iki 20 sekundžių, paprastai sumažina įsotinimą deguonimi 3-4 proc. Paradoksinio miego metu apnejja gali siekti net 60 sekundžių, o nutukusiems įsotinimas deguonimi gali sumažèti iki 60 proc. Jei apnẻja ilgesnè nei 1-2 min., gali prasidèti smegenų išemijos sukeliami naktiniai epilepsijos priepuoliai.

\section{LITERATŪRA}

1. Liesienè V, Pauza V. Miego medicina. Kaunas 1999

2. Coeleman RM, Roffwarg HP, Kennedy SJ et al. Sleep wake disorders based on polysomnographic diagnosis. A national cooperative study // J. Am. Med. Assoc. 1982;247:997-1003.

3. Roehrs T, Zorick F, Wittig R, Conway W, Roth T. Predictors of objective level of daytime sleepines in patients with sleep-related breathing disorders. Chest 1989;95:1202-1206.

4. He J, Kryger MH, Zorick FJ, Conway W, Roth T. Mortality and apnea index in obstructive sleep apnea: experience in 385 male patients. Chest 1988;94:91-14.

5. Counseil d'evalution des technologies de la sante du Quebec. Treatment of obstructive sleep apnea by nasal continuous positive airway pressure. Canadian Sleep Society 1990.

6. Levy P, Pepin JL, Mayor P, Wuyam B, Veale D. Management of simple snoring, upper airway resistance syndrome and moderate sleep apnea. Sleep 1996;19:s101-s110

7. Marin J, Baddorey I, Martin T, Carrizo S. Long term survival of untreated patients with obstructive sleep apnea: a prospective study. Eur Respir 1996;23:22s.

8. Strohl KP, Redline S. Recognition of obstructive sleep apnea. Am J Respir Crit Care Med 1996:154:279-289.

9. Flemons WW, McNicholas WT. Clinical prediction of the obstructive sleep apnea syndrome. Sleep Med Rev 1997;1:s13-s16.

10. Deegan PC, McNicholas WT. Predictive value of clinical fetures for the obstructive sleep apnoea syndrome. Eur Respir J 1996;I.9:117-124.

11. Dealberto MJ, Ferber C, Garma L, Lemoine P, Alpetrovitch A. Factors related to sleep apnea syndrome in sleep clinic patients. Chest 1994;105:1753-1758.

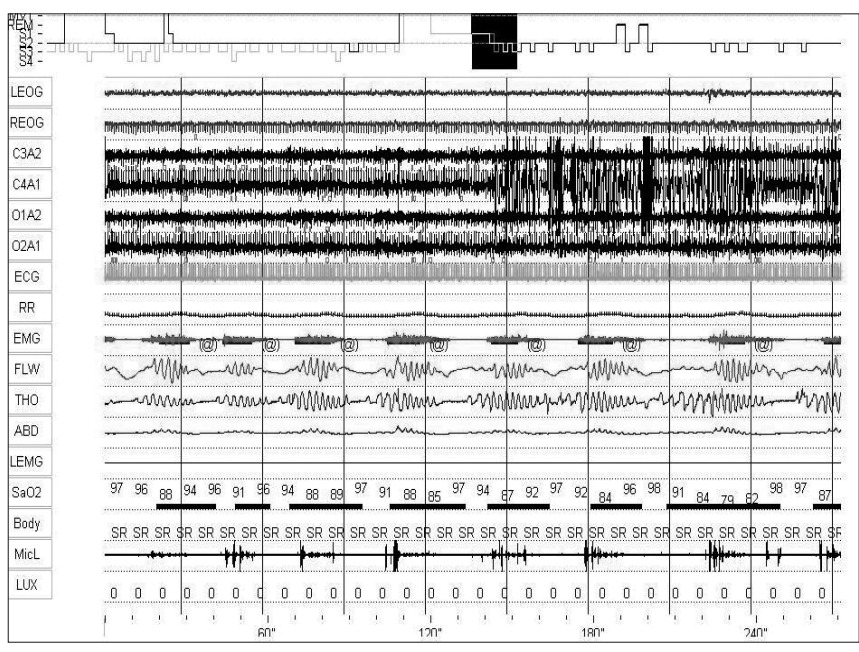

5 pav. OBSTRUKCINE MIEGO APNĖJA SERGANČIO LIGONIO POLISOMNOGRAMA

OMA klasifikuojama pagal apnèjos ir hipopnejos indeksą bei mieguistumo lygmenị. Pagal apnejos ir hipopnejos indeksą (epizodų skaičių per valandą) OMA gali būti lengva (5-15), vidutine (15-30) ir sunki (per 30). Pagal mieguistumą OMA gali būti lengva/vidutinè (nepavojingas mieguistumas) ir sunki (nekontroliuojamas, pavojingas mieguistumas).

\section{DIAGNOSIS OF RESPIRATORY DISORDERS DURING SLEEP}

SKAIDRIUS MILIAUSKAS

DEPARTMENT OF PULMONOLOGY AND IMMUNOLOGY KAUNAS UNIVERSITY OF MEDICINE

Keywords: obstructive sleep apnea, central sleep apnea, sleepiness, polysomnography.

Summary. Recent literary data concerning diagnosis of respiratory disorders during sleep, evaluating of daytime sleepiness have been reviewed. Principles of polysomnography have been discussed.

12. Crocker BD, Olson LG, Saunders NA, et al. Estimation of the probability of disturbed breathing during sleep before a sleep study. Am Rev Respir Dis 1990;142:14-18.

13. Vinner S, Szalai JP, Hoffstein V. Are history and physical examination a good screening test for sleep apnea. Ann Intern Med 1991;115:.356-359.

14. Hoffstein V, Szalai JP. Predictive value of clinical features in diagnosing obstructive sleep apnea. Sleep 1993;16:118-122.

15. A manual of Standartized Terminology, Techniques and Scoring System for Sleep Stages of Human Subjects. University of California 1977.

16. Miliauskas S, Sakalauskas R. Deguonies isotinimo ypatybès sergant obstrukcine miego apneja. Medicina 2005;41:217 - 220.

17. Miliauskas S, Sakalauskas R. Miego fragmentacijos ir nakties saturacijos sutrikimai sergantiems obstrukcinès miego apnèjos-hipopnejos sindromu su ir be lètinès obstrukcinès plaučių ligos. Medicina 2001;37: 885889.

18. McNicholas WT, Calverley PMA, Lee A, et al. Long - acting inhaled anticholinergic therapy improves sleeping oxygen saturation in COPD. Eur Resp J 2004; 23; 825 - 831.

19. McNicholas WT. Sleep apnoea sindrome. Breathe 2005;1:219-227.

20. Lanfranchi PA, Somers VK. Sleep-disordered breathing in heart failure: characteristics and implications Respir Physiol Neurobiol 2003;136:15365.

21. Marin JM, Carrizo SJ, Vicente E, Agusti AG. Long-term cardiovascular outcomes in men with obstructive sleep apnoea-hypopnoea with or without treatment with continuous positive airway pressure: an observational study 2005 Mar 19-25;365(9464):1046-53. 